\title{
THE
}

\section{A Multigenerational Field Experiment on Eco-evolutionary Dynamics of the Influential Lizard Anolis sagrei: A Mid-term Report}

Thomas W. Schoener

Jason J. Kolbe

University of Rhode Island, jjkolbe@uri.edu

Manuel Leal

Jonathan B. Losos

David A. Spiller

Follow this and additional works at: https://digitalcommons.uri.edu/bio_facpubs

The University of Rhode Island Faculty have made this article openly available. Please let us know how Open Access to this research benefits you.

This is a pre-publication author manuscript of the final, published article.

Terms of Use

This article is made available under the terms and conditions applicable towards Open Access

Policy Articles, as set forth in our Terms of Use.

\section{Citation/Publisher Attribution}

Thomas W. Schoener, Jason J. Kolbe, Manuel Leal, Jonathan B. Losos, and David A. Spiller "A Multigenerational Field Experiment on Eco-evolutionary Dynamics of the Influential Lizard Anolis sagrei: A Mid-term Report," Copeia 105(3), (27 September 2017). https://doi.org/10.1643/CE-16-549

Available at: https://doi.org/10.1643/CE-16-549 
A Multigenerational Field Experiment on Ecoevolutionary Dynamics of the Influential Lizard Anolis sagrei: A Mid-term Report

Thomas W. Schoener ${ }^{1}$, Jason J. Kolbe ${ }^{2}$, Manuel Leal ${ }^{3}$, Jonathan B. Losos ${ }^{4}$,

Running head: Eco-evolutionary dynamics of an influential lizard

${ }^{1}$ Department of Evolution and Ecology, University of California, Davis CA 95616 (twschoener@ucdavis.edu,daspiller@ucdavis.edu)

${ }^{2}$ Department of Biological Sciences, University of Rhode Island, Kingston, RI 02881 (jjkolbe@uri.edu)

${ }^{3}$ Division of Biological Sciences, University of Missouri, Columbia, MO 65211 (lealm@missouri.edu)

${ }^{4}$ Museum of Comparative Zoology and Department of Organismic and Evolutionary Biology, Harvard University, Cambridge, MA 02138 (jlosos@,oeb.harvard.edu) 
(ABSTRACT)

Only a handful of multi-generational experiments in natural systems of eco-evolutionary dynamics currently exist, despite Fussmann et al.'s call for more such studies nearly a decade ago. To perform such a study, in 2008 we introduced the lizard Leiocephalus carinatus, a predator (and possible food competitor) of the lizard Anolis sagrei, to seven islands having A. sagrei, with seven unmanipulated islands having A. sagrei as controls. Almost immediately, L. carinatus, which is larger and more terrestrial than $A$. sagrei, caused a major habitat shift in $A$. sagrei away from the ground and toward higher and thinner perches; focal behavioral surveys showed that on islands where its predator was introduced, A. sagrei had less conspicuous visual displays. The expected pattern for density of $A$. sagrei is that it would decrease markedly at first via predation from the larger lizard, but then it would increase as the habitat shift selected for individuals better able to live in higher vegetation. Data through 2015 show this pattern, but a return to previous densities (time-by-treatment interaction) was not yet significant. A previous within-generation selection study and comparative data suggest that short legs should evolve as the lizards adapt to better maneuver on the thin perches of higher vegetation. However, no indication of the expected morphological change in limb length was present through 2015. Previous studies showed $A$. sagrei producing many effects on lower levels of the food web, some quite large. In this study through 2012, we found significant differences only in spiders (web and ground). A possible complication is that the study site was hit by two major hurricanes in the last five years, decreasing population sizes of both lizard species and reducing the experimental perturbations. A benefit of the hurricanes, however, is that they eliminated lizards from some islands, providing the opportunity to monitor natural recolonization, the frequency of which has eco-evolutionary implications. Annual surveys of the 46 islands that lost lizards showed that recolonization is rather slow. To explore long-term patterns of morphological variation, we monitored morphology of 31 island populations for up to 19 years. Mean limb length oscillated across the 19-year period, both increasing and decreasing substantially, yet the net effect over 
62 that period is almost no change. In years following hurricanes, limb length increases significantly more 63 than expected by chance.

64 
The effect of ecological change on evolution has been a common theme for many years, but the reverse - how evolutionary dynamics affect ecological traits such as population growth rate — has only recently begun to take hold with the increasing realization that evolution can occur over ecological time scales (Schoener, 2011, 2013; DeLong et al. 2016). In 2007, Fussmann et al. surveyed the literature for examples that provided empirical support for eco-evolutionary dynamics using four criteria: (1) Does the study document population change over several generations? (2) Is there a record of genetic frequencies and their changes over time? (3) Is the mechanistic link between ecological and evolutionary dynamics plausible? (4) Is there a control? Only eight studies were found that partially supported their criteria, and none were experimental studies in the field. There have been numerous relevant studies since this survey, some of which supported one or both of the evo-to-eco and eco-to-evo links (see especially Turcotte et al., 2011 and Agrawal et al., 2013; Hendry and Kinnison 1999, Reznick and Ghalambor 2001, Hariston et al. 2005, Saccheri and Hanski 2006, Ezard et al. 2009, Coulson et al. 2011; various papers this volume, including Kindsvater and Palkovacs, Tuckett et al., Urban et al; recent partial reviews in Ellner [2013],

81 Hiltunen et al. [2015], Schoener [2013], Schoener et al. [2014]). However, moderately long-term,

82 substantially multi-generational experiments in natural systems of eco-evolutionary dynamics-

83 particularly how evolution affects ecology_remain elusive.

87 present study, we selected 14 islands with natural populations of the lizard Anolis sagrei and introduced 88 the larger, mostly terrestrial lizard Leiocephalus carinatus (a known predator of smaller lizards [Schoener et al., 1982]) onto seven randomly chosen islands, leaving the other seven islands as controls. Each year, 
91 diameter), morphological traits, and various components of the lizard-topped food web. In addition to the

92 experimental islands, we monitored food-web components on three islands with no lizards to assess the

93 effects of lizards.

94 This experiment has yielded major abundance change (great decrease), habitat-use change (upward

95 shift to narrower perches), and other behavioral change (e.g. in signaling behavior [Steinberg et al. 2014])

96 in A. sagrei, as well as some food-web effects. However, it has produced no significant morphological

97 change in lizard limb length and only a suggestive change in A. sagrei abundance in the direction

98 predicted by adaptive ecological change. A possible explanation for these so-far negative results is the

99 severe effects of two hurricanes - Irene (2011) and Sandy (2012)—which exterminated A. sagrei on some

100 islands while on others greatly lowered their abundance as well as that of their predator L. carinatus. We

101 have taken advantage of these hurricanes to monitor the natural recolonization by lizards of islands from

102 which they were exterminated. Such disturbance must have greatly affected the strength and even

103 possibly the direction of selection, plausibly forestalling the expected morphological changes.

What follows is a progress report of ongoing efforts to understand the multifaceted nature of the eco-

evolutionary feedbacks in A. sagrei in response to biotic (predator additions) and abiotic (hurricanes)

106

perturbations and the cascading impacts on the rest of our island food webs. We begin by describing the

107 temporal progression of habitat use, density and morphology found for $A$. sagrei after introduction of the

108 larger predator. We then discuss effects of the manipulation on other levels of the food web: various kinds

109 of arthropods and plants. We summarize the data on natural colonization by A. sagrei in the wake of

110 extinctions caused by the two hurricanes, and we explore long-term data on morphological change in the

111 aftermath of hurricanes.

112 EFFECT OF THE LARGER LIZARD ON HABITAT USE OF THE SUBJECT LIZARD. We

113 predicted that the introduction of the ground-dwelling predatory lizard L. carinatus would force A. sagrei

114 to shift its habitat use up into the vegetation, decreasing the percentage of the time it was found on the

115 ground, increasing its average perch height and decreasing its average perch diameter. We visited each

116 island multiple times during annual fieldwork in May and recorded structural habitat use (i.e., perch 
117 height and diameter in $\mathrm{cm}$ ) for every undisturbed lizard encountered. For perch height and all other

118 response variables, we used repeated-measures MANOVA, an alternative designation for "multivariate

119 repeated measures", with treatment (A. sagrei with L. carinatus introduced, A. sagrei alone) as the main

120 between-subjects factor, time (2009-2015) as the repeated within-subjects factor, and the treatment-by-

121 time interaction. Sphericity was significant $(\mathrm{p}<0.03)$ for this and all other analyses except morphology $(\mathrm{p}$

$122=0.064)$; therefore the multivariate approach was used in all analyses for consistency. The predicted

123 shifts occurred soon after the introduction of the predatory lizard and have been maintained over the six-

124 year period (Figs. $1 \& 2$ ). Moreover, focal behavioral surveys indicate that $A$. sagrei has altered its

125 behavior: on islands on which the predator was introduced, A. sagrei produces less conspicuous visual

126 displays (Steinberg et al., 2014).

127

128

EFFECT OF THE LARGER LIZARD ON DENSITIES OF THE SUBJECT LIZARD. Strauss et al.

129 (2008) have argued that evolutionary change in the focal species may often influence effect size of

treatments in ecological field experiments, given that ecological and evolutionary time can be

commensurate. For a negative interaction such as predation, Strauss et al. (2008) hypothesized that the

132 effect size should first increase as the prey is diminished by the predator, then decrease as the prey adapt,

133 evolving morphologies and other kinds of traits more appropriate to their new situation and thereby

134 eventually increasing the prey density. Indeed, lack of apparent change of ecological traits such as

135 population size may reflect much ongoing evolution (Kinnison et al., 2015). Although there are various

136 relevant field studies (e.g. Bassar et al., 2012; Harmon et al., 2009; Ingram et al., 2012; Palkovacs et al.,

137 2009; Simon et al. THIS VOLUME AND OTHERS CITED ABOVE), as well as numerous lab studies

138 (reviewed in Hiltunen et al., 2015; Schoener, 2013; Schoener et al., 2015), to our knowledge the specific

139 predation effect suggested in Strauss et al. (2008) is not yet demonstrated in the field.

140 To estimate population size of A. sagrei on entire islands (which are closed systems), we used log-

141 linear capture-recapture methods (Fienberg et al., 1999), which are promoted by an international working

142 group including Fienberg, Buckland, Seber and Cormack (Fienberg, pers. comm.). These methods have 
143

144

been described as particularly useful for modeling the capture dependencies between censuses that weather imposes on our system (Schwarz and Seber, 1999).

Introduction of the larger lizard resulted in a marked decrease in the density of A. sagrei (Fig. 3). Densities first diverge and then converge: before Hurricane Sandy (which occurred in 2012) the effect of L. carinatus on A. sagrei density was significant (2009-2012, $\left.\mathrm{F}_{1,7}=6.9, \mathrm{p}=0.034\right)$, but not after Sandy $\left(2013-2015, \mathrm{~F}_{1,7}=1.7, \mathrm{p}=0.236\right)$. The time-by-treatment interaction (the test for whether a return to preexperimental densities occurs, run for the entire time series) is not significant, however $\left(2009-2015, \mathrm{~F}_{6,2}=\right.$ $5.4, p=0.165$, repeated-measures MANOVA). In view of our results on leg length, this is perhaps not surprising, as there is no significant difference in leg length through the same period of time (see below). Given the results in a previous experiment (Losos et al., 2006) in which survival selection did shift over time toward favoring shorter limbs (Fig. 4), we predict that without further severe disturbance we will eventually find a significant decrease in effect size as the lizards adapt to living in the arboreal matrix. Indeed, in a different experiment undisturbed by hurricanes (Schoener and Spiller, 1999), we found a similar reversal in effect size over the course of seven years: upon introduction of $A$. sagrei, plant damage first increased, then decreased back to the pre-introduction value, perhaps due to in part to adaptation by the herbivore prey.

\section{EFFECT OF THE LARGER LIZARD ON LIMB LENGTH OF THE SUBJECT LIZARD. Both}

comparative and biomechanical studies make clear predictions about how $A$. sagrei will adapt to its use of narrower perches in the presence of L. carinatus: species that use broad surfaces, such as tree trunks or the ground, evolve long hindlegs and tails, whereas species specialized to use narrow surfaces have shorter limbs and tails. In addition, more arboreal species tend to have narrow heads and well-developed toepads. These trends have evolved independently on four Greater Antillean islands and among A. sagrei populations on islands in the Bahamas and elsewhere (Lister, 1976; Williams, 1983; Losos et al., 1994, 1998; Calsbeek et al., 2006); however, whether population-level changes are the result of adaptive phenotypic plasticity or genetic change is always an issue. Although anoles do exhibit phenotypic 
plasticity in limb length (Losos et al., 2000; Kolbe and Losos, 2005), in at least some of these cases genetic change seems the more likely explanation (Kolbe et al., 2012).). Biomechanical models predict that lizards using narrower surfaces should evolve shorter legs, narrower heads, and larger toepads (reviewed in Losos, 2009). In accordance with these trends, our previous selection experiments revealed that once A. sagrei occupied higher and narrower vegetation on islands that had the predator introduced, selection favored shorter limb length (Fig. 4 taken from Losos et al., 2006]).

To characterize trait change, we collected, measured and returned lizards to their point of capture within 24 hours. We analyzed skeletal morphology from images collected with a field-portable, custombuilt, digital x-ray system (minimum image dimensions 1500 x 1900; X-ray Associates East), which we used to measure snout-vent length (SVL) and tibia length using ObjectJ (https://sils.fnwi.uva.nl/bcb/objectj/), a plug-in for ImageJ (Schneider et al., 2012). We calculated mean relative tibia length as the residuals of the regression of log-tibia on $\log -\mathrm{SVL}$, separately for each sex, and then calculated a mean for islands in each year (2008-2015) with the sexes combined. Despite the strong effects of the predatory lizard on $A$. sagrei habitat use and density (see above), to date there is no evidence of any difference in hindlimb morphology between populations on experimental and control islands (Fig. 5). We hypothesize that the lack of an effect may be the result of Hurricanes Irene and Sandy. Not only did A. sagrei populations greatly decrease on many islands, but the populations of the predatory lizard were reduced as well; consequently, for several years, the selective effect of the experimental treatment may have been minimized. Indeed, there is a 0.83 ordinary Pearson correlation between perch-height effect size (log treatment/control) and mean number of L. carinatus per island in a given year. We plan to continue to monitor the islands on a yearly basis: now that the islands and their populations have recovered from the hurricanes, we expect that the treatments will begin to diverge in morphology. 
attempt to experimentally document evolutionary trait-mediated indirect effects (Ohgushi et al., 2013), we measured a number of food web attributes: (1) Web spiders were censused by searching the entirety of each island and recording the species identity and web height of each spider individual or fresh web observed. (2) Relative abundance of aerial arthropods was measured on 2-3 focal buttonwood shrubs (see below) on each island using sticky traps $\left(22 \times 14 \mathrm{~cm}\right.$ sheets of clear plastic coated with Tangletrap ${ }^{\circledR}$ adhesive and tied to the vegetation). On each shrub, one trap was tied in the upper vegetation (1-2 m above ground) and one was tied lower (0.2-0.5 m). After $24 \mathrm{hr}$, body length and taxon (to order or lower when possible) of each arthropod caught in each trap was recorded in the field. (3) Ground arthropods were sampled with plastic bowls filled with $500 \mathrm{ml}$ of water and a trace amount of detergent. Two bowls were placed on the ground under each focal shrub and specimens caught after $24 \mathrm{hr}$ were preserved. (4) We measured leaf damage and foliage growth on 2-3 buttonwood (Conocarpus erectus) shrubs on each island from May to December as follows. In May, on each shrub, three randomly chosen branches were tagged in the upper (1-2 $\mathrm{m}$ above ground) and in the lower (0.2-0.5 m) vegetation layers. On each branch, the most distal leaves present were marked with ink. In December, only leaves that emerged after May (those more distal than the marked ones) were collected. Sampled leaves were immediately pressed and then photographed. Total leaf and damaged areas were measured digitally from photographs using SigmaScan Pro Image Analysis System. Percent of the leaf area damaged on each shrub was computed by summing the total and damaged areas of all the leaves sampled. We categorized three difference types of damage: holes, scars and lines. Growth rate per branch was the sum of the total leaf areas that emerge 214 from May to December. responded in previous experiments (Schoener et al., 2002, and references therein). Web-spider density

217 immediately increased on introduction islands and tended to remain higher than on islands with only $A$.

218 sagrei present (repeated measures ANOVA: $\mathrm{F}_{1,13}=6.33, \mathrm{p}=0.026$; Effect size $(\log$ ratio $\left.)=0.24\right)$. We

219 suggest that the positive effect of $L$. carinatus on web spiders was indirect: large lizards reduced the 
density of the small lizard (the major web-spider predator), which increased web spiders. We found no significant difference between treatments in the height of webs above the ground (repeated measures ANOVA: $\mathrm{F}_{2,12}=1.71, \mathrm{p}=0.22$ ). Numbers of cursorial spiders (mostly lycosids and salticids) were higher on islands with lizards absent than on islands with only $A$. sagrei (repeated measures ANOVA: $\mathrm{F}_{1,14}=$ 45.21, $\mathrm{p}=0.0001$; Effect size $=1.26)$ and were higher on $L$. carinatus introduction islands than on islands with only A. sagrei $\left(\mathrm{F}_{1,13}=6.85, \mathrm{p}=0.021\right.$; Effect size $\left.=0.46\right)$. As for the web-spiders, we suggest that the negative effect of small lizards on cursorial spiders was direct, whereas the positive effect of large lizards was indirect. Although there was no significant overall difference among treatments in the number of springtails caught in bowls (repeated measures ANOVA: $\mathrm{F}_{2,13}=1.30, \mathrm{p}=0.31$ ), in 2011 they were noticeably lower on introduction islands than on islands with only small lizards (ANOVA: $\mathrm{F}_{1,14}=4.90$, $\mathrm{p}=0.044$; Effect size $=0.35)$ and on no-lizard islands than on islands with only small lizards $\left(\mathrm{F}_{1,14}=5.55\right.$, $\mathrm{p}=0.034$; Effect size $=0.61$ ). We suggest that this pattern might be caused by a 4-level trophic cascade in which large lizards reduce small lizards, leading to an increase in cursorial spiders which decreases springtails. We expected the more arboreal arthropods to decline with the increasingly arboreal adaptation of $A$. sagrei and plant damage from arthropod herbivory to decrease disproportionately in the higher vegetation, but neither happened. Nor was there an effect on foliage growth. Nothing has substantially changed through 2015. Because the morphological changes are not yet in the predicted direction, it is unsurprising that most food-web expectations are unfulfilled. Hence as above, we can attribute the lack of response to effects of hurricanes: recall (see above) that Anolis sagrei populations were not only greatly decreased on many islands, but the populations of the predatory lizard were greatly reduced; consequently, for several years, the selective effect of the experimental treatment may have been minimized.

\section{EFFECT OF HURRICANES ON THE EXPERIMENTAL SYSTEM. We are currently yearly} monitoring 46 islands that have had A. sagrei in the past (all were monitored for at least six years, and some for decades). Of those, 27 islands had their populations exterminated by Hurricane Sandy (as 
determined in 2013 censuses). Only three of those 27 were recolonized in 2014 (although one of the nolizard control islands was colonized for the first time), and one was recolonized in 2015. Hurricanes have had devastating effects on some islands in our experiments, but here is one benefit: by clearing all lizards from relatively large islands, for the first time we are able to measure lizard recolonization of islands of this size. Our genetic studies have allowed us to estimate rates of immigration onto already occupied islands (Kolbe et al., 2012), and from those we might have expected relatively high recolonization rates. However, the results to date do not support this expectation; recolonization rates have been very low, even for islands much larger than the local threshold area for A. sagrei (see also Schoener and Schoener, 1983a,b).

Our current study is embedded in a much longer-term study. Over the past two decades, we have been tracking $A$. sagrei morphology in 31 populations in the same region. Some islands were part of previous experiments; some have never been included in any of our previous studies. Over this 19-year period, mean limb length has barely changed. However, this stasis is more apparent than real, as limb length has varied markedly over this period (Fig. 6). Research on Darwin's finches has illustrated how long periods of little net evolutionary change can result from oscillating selection (Grant and Grant, 2014) -- i.e., directional selection that alternates in direction (Gibbs and Grant, 1987). The prevalence of oscillating selection is currently debated (Siepielski et al., 2009, 2013; Morrissey and Hadfield, 2012), and the extent to which long-term stasis is the result of alternating selection is unclear. Our time series suggests such a pattern: in years following hurricanes, limb length tends to increase, followed by a decline (Fig. 6): all four years after a hurricane show an increase, and three of those four are the largest increase in the time series. A Monte Carlo simulation was performed, in which we computed 1000 random arrangements of the four hurricanes over the time series and computed as the test statistic the signed change in limb length the year before a given year. The increase in limb length after a hurricane year is unusually large: the two-tailed $\mathrm{P}=0.005$, that is, only 0.5 percent of 1000 random arrangements of the four hurricanes over the time series give a more extreme difference in either direction than the observed. We will continue to measure morphology for lizards on these islands, as well as measure the morphology 
272 of any newly-established populations resulting from natural colonization (including the three recent

273 populations we have detected in the last three years). Our prediction is that limb length will decline across

274 all populations in the absence of further hurricanes but will increase if the islands are hit by another

275 hurricane.

276 CONCLUSION. We caution that the results herein represent an interim report. As described, certain

277 results (A. sagrei habitat shifts) are exceptionally strong, certain results (A. sagrei density changes, a few

278 food-web effects) are moderate, and certain results (A.sagrei morphological changes) show no trend so

279 far. Hurricanes have impacted the study site greatly during the course of the experiment, and these may

280 have slowed down some of the expected eco-evolutionary changes and food-web effects, a possibility we

281 will hopefully be able to assess in a few years. Indeed, extreme climatic events may often reset the

282 pathway that eco-evolutionary dynamics is following, a possibility explored further in a recent Gordon

283 conference keynote address (T.W. Schoener, unpublished), and which is an example of context-

284 dependence as conceptualized by Tuckett et al. (THIS VOLUME). Hurricanes have not been an

285 unmitigated negative, however: they have allowed us to gather unique data on natural recolonization rates

286 as well as study their possible effects on morphological and other traits. Our exploratory finding that $A$.

287 sagrei hindlimb length increases after the four hurricanes over the past 19 years generates the testable

288 hypothesis that hurricanes select for longer legs, a phenomenon that we are actively investigating both

289 empirically and theoretically. Ultimately, our goal is to tie together the effects of major disturbances, in

290 our case hurricanes, to chronic eco-evolutionary dynamics in metacommunities.

291

292 ACKNOWLEDGMENTS. We thank NSF and the National Geographic Society for support, the

293 Bahamas government for permission to do this research, and Buddy Pinder for boat transport. Many

294 people assisted with fieldwork, including Sean Giery, Oriol Lapiedra, James Stroud, Yoel Stuart, and

295 Amber Wright. 


\section{LITERATURE CITED}

Agrawal, A.A., M.T.J. Johnson, A.P. Hastings, and J.L. Maron. 2013. Experimental evolution of plant life-history traits and its eco-evolutionary feedback to seed predator populations. American Naturalist 181:S35-S45.

Bassar, R. D., R. Ferriere, A. López-Sepulcre, M.C. Marshall, J. Travis, C.M. Pringle, and D.N. Reznick. 2012. Direct and indirect ecosystem effects of evolutionary adaptation in the Trinidadian Guppy (Poecilia reticulata). American Naturalist 180:167-185.

Calsbeek, R., J.H. Knouft, and T.B. Smith. 2006. Variation in scale numbers is consistent with ecologically based natural selection acting within and between lizard species. Evolutionary Ecology 20:377-394.

Coulson, T., D. R. MacNulty, D. R. Stahler, B. vonHoldt, R. K. Wayne, and D. W. Smith. 2011. Modeling effects of environmental change on wolf population dynamics, trait evolution, and life history. Science 334.6060:1275-1278.

DeLong, J. P., V.E. Forbes, N. Galic, J.P. Gibert, R.G. Laport, J.S. Phillips, and J.M. Vavra. 2016. How fast is fast? Eco-evolutionary dynamics and rates of change in populations and phenotypes. Evolution and Ecology on line January 9, 2016.

El-Sabaawi, R. THIS VOLUME.

Ellner, S.P. 2013. Rapid evolution: from genes to communities, and back again? Functional Ecology 27: 1087-1099.

Ezard, T. H. G., S. D. Cote, and F. Pelletier. 2009. Eco-evolutionary dynamics: Disentangling phenotypic, environmental and population fluctuations. Philosophical Transactions of the Royal Society of London B 364:1491-1498.

Fienberg, S.E., M. Johnson, and B. Junker. 1999. Classical multi-level and Bayesian approaches to population-size estimation estimation using data from multiple tests. Journal of the Royal Statistical Society (A) 162:383-406. 
Fussmann, G.F., M. Loreau, and P. A. Abrams. 2007. Eco-evolutionary dynamics of communities and ecosystems. Functional Ecology 21:465-477.

Gibbs H.L., and P.R. Grant. 1987. Oscillating selection on Darwin's finches. Nature 327:511-513.

P.R. Grant, PR., and B.R. Grant. 2014. 40 Years of Evolution: Darwin's Finches on Daphne Major Island. Princeton University Press: Princeton, NJ.

Hairston, N. G., Jr., S. P. Ellner, M. A. Geber, T. Yoshida, and J. Fox. 2005. Rapid evolution and the convergence of ecological and evolutionary time. Ecology Letters 8:1114-1127.

Hanski, I. 2001. Population dynamic consequences of dispersal in local populations and in metapopulations. Pages 283-298 in J. Clobert, E. Danchin, J. D. Nichols, \& A. A. Dhondt, Eds. Dispersal. Oxford University Press, Oxford.

Harmon, L.J., B. Matthews, S. Des Roches, J.M. Chase, J.B. Shurin, and D. Schluter. 2009. Evolutionary diversification in stickleback affects ecosystems functioning. Nature 458:11671170.

Hendry, A. P. 2017. Eco-evolutionary Dynamics. Princeton Univ. Press, Princeton, NJ.

Hendry, A. P., and M. T. Kinnison. 1999. The pace of modern life: Measuring rates of contemporary microevolution. Evolution 53.6:1637-1653.

Holt, R.D., and J. H. Lawton. 1993. Apparent competition and enemy-free space in insect host-parasite communities. American Naturalist 142:623-645.

Hiltunen, T., S.P. Ellner, G. Hooker, L. E. Jones, and N.G. Hairston Jr. 2015. Eco-evolutionary dynamics in a three-species food web with intraguild predation: intriguingly complex. Advances in Ecological Research 50:41-73.

Inchausti, P., and J. Halley. 2003. On the relation between temporal variability and persistence time in animal populations. Journal of Animal Ecology 72:899-908.

Ingram, T., R. Svanback, N.J.B. Kraft, P. Kratina, L. Southcott, and D. Schluter. 2012. Intraguild predation drives evolutionary niche shift in three-spine stickleback. Evolution 66:1819-1832. 
Kindsvater, H. K., and E. P. Palkovacs. THIS VOLUME.

Kinnison, M. T., M. J. Unwin, and T. F. Quinn. 2008. Eco-evolutionary vs. habitat contributions to invasion in salmon: Experimental evaluation in the wild. Molecular Ecology 17:405-414.

Kinnison, M.T., N. G. Hairston, and A. P. Hendry. 2015. Measuring rates of contemporary microevolution. Evolution 53.6:1637-1653.

Kolbe, J.J., and J.B. Losos. 2005. Hind-limb length plasticity in Anolis carolinensis. Journal of Herpetology 39:674-678.

Kolbe, J.J., M. Leal, T.W. Schoener, D.A. Spiller, and J. B. Losos. 2012. Founder effects persist despite adaptive differentiation: A field experiment with lizards. Science 335:1086-1089.

Legendre, S., T.W. Schoener, J. Clobert, and D. A. Spiller. 2008. How is extinction rate related to population-size variability over time? A family of models for species with repeated extinction and immigration. American Naturalist 172:282-298.

Lister, B. C. 1976. The nature of niche expansion in West Indian Anolis lizards II. Evolutionary components. Evolution 30:677-692.

Losos, J. B. 2009. Lizards in an Evolutionary Tree: Ecology and Adaptive Radiation of Anoles. University of California Press, Berkeley CA.

Losos, J.B., D.A. Creer, D. Glossip, R. Goellner, A. Hampton, G. Roberts, N. Haskell, P. Taylor, and J. Etling. 2000. Evolutionary implications of phenotypic plasticity in the hindlimb of the lizard Anolis sagrei. Evolution 54:301-305.

Losos, J. B., D. J. Irschick, and T. W. Schoener. 1994. Adaptation and constraint in the evolution of specialization of Bahamian Anolis lizards. Evolution 48:1786-1798.

Losos, J. B., T.R. Jackman, A. Larson, K. de Queiroz, and L. Rodríguez-Schettino. 1998. Contingency and determinism in replicated adaptive radiations of island lizards. Science 279:2115-2118. 
Losos, J. B., T.W. Schoener, R.B. Langerhans, and D.A. Spiller. 2006. Rapid temporal reversal in predator-driven natural selection. Science 314:1111.

Morrissey, M.B., and J. D. Hadfield. 2012. Directional selection in temporally replicated studies is remarkably consistent. Evolution 66:435-442.

Ohgushi T., O. Schmitz, and R.D. Holt, Eds. 2012. Trait-Mediated Indirect Interactions: Ecological and Evolutionary Perspectives. Cambridge University Press: Cambridge, UK.

\section{Palkovacs, E.P., M.C. Marshall, B.A. Lamphere, B.R. Lynch, D.J. Weesel, D.F. Fraser, D.N.} Reznick, C. M. Pringle, and M.T. Kinnison. 2009. Experimental evaluation of evolution and coevolution as agents of ecosystem change in Trinidadian streams. Philosophical Transactions of the Royal Society B 364:1617-1628.

Reznick, D. N., and C. K. Ghalambor. 2001. The population ecology of contemporary adaptations: What empirical studies reveal about the conditions that promote adaptive evolution. Genetica 112-113:183-198.

Saccheri, I., and I. Hanski. 2006. Natural selection and population dynamics. Trends in Ecology and Evolution 21.6:341-347.

Schneider, C. A., W. S. Rasband, and K. W. Eliceiri. 2012. NIH Image to ImageJ: 25 years of image analysis. Nature Methods 9:671-675.

Schoener, T. W. 2011. The newest synthesis: Understanding the interplay of evolutionary and ecological dynamics. Science 330:426-429.

Schoener, T.W. 2013. "Eco-Evolutionary Dynamics." in D. Gibson, Ed., Oxford Bibliographies in Ecology. Oxford University Press, online resource.

Schoener, T.W., and A. Schoener. 1983a. The time to extinction of a colonizing propagule of lizards increases with island area. Nature 302:332-334.

Schoener, T.W., and A. Schoener. 1983b. Distribution of vertebrates on some very small islands. I. Occurrence sequences of individual species. Journal of Animal Ecology 52:209-235. 
Schoener, T.W., J.B. Slade, and C.H. Stinson. 1982. Diet and sexual dimorphism in the very catholic lizard genus, Leiocephalus, of the Bahamas. Oecologia 53:160-169.

Schoener, T.W., and D.A. Spiller. 1999. Indirect effects in an experimentally staged invasion by a major predator. American Naturalist 153:347-358.

Schoener, T.W., D.A. Spiller, and J.B. Losos. 2002. Predation on a common Anolis lizard: Can the food-web effects of a devastating predator be reversed? Ecological Monographs 73:383-407.

Schoener, T.W., J. Clobert, S. Legendre, and D. A. Spiller. 2003. Life-history models of extinction: A test with island spiders. American Naturalist 162:558-573.

Schoener, T.W. J.B. Losos, and D.A. Spiller. 2005. Island biogeography of populations: An introduced species transforms survival patterns. Science 310:1807-1809.

Schoener, T.W., J. Moya-Larano, and J. Rowntree. 2014. Eco-evolutionary dynamics PREFACE. Advances in Ecological Research 50:XIII-XX.

Schwartz, C.J., and G.A.F. Seber. 1999. A review of estimating animal abundance III. Statistical Science 14: 427-456.

Siepielski, A.M., J.D. DiBattista, and S.M. Carlson. 2009. It's about time: the temporal dynamics of phenotypic selection in the wild. Ecology Letters 12:1261-1276.

Siepielski, A.M., K.M. Gotanda, M.B. Morrissey, S.E. Diamond, J.D. DiBattista, and S.M. Carlson. 2013. The spatial patterns of directional phenotypic selection. Ecology Letters 16:1382-1392.

Simon, T.N. et al. THIS VOLUME.

Steinberg, D.S., J. B. Losos, T.W. Schoener, D.A. Spiller, J. Kolbe, and M. Leal. 2014. Predationassociated modulation of movement-based signals by a Bahamian lizard. Proceedings of the National Academy of Sciences of the United States of America 111:9187-9192.

Strauss, S. Y., J. A. Lau, T.W. Schoener, and P. Tiffin. 2008. Evolution in ecological field experiments: implications for effect size. Ecology Letters 11:199-207.

Tuckett, Q.M. et al. THIS VOLUME. 
429 Turcotte, M.M., D.N. Reznick, and J. D. Hare. 2011. The impact of rapid evolution on population dynamics in the wild: Experimental test of eco-evolutionary dynamics. Ecology Letters 14:10841092.

432 Urban M.C. et al. THIS VOLUME.

433 Williams, E. E. 1983. Ecomorphs, faunas, island size, and diverse end points in island radiations of Anolis. Pages 326-370 in R.B. Huey, E.R. Pianka, and T.W. Schoener, Eds., Lizard Ecology: Studies of a Model Organism. Harvard University Press. Cambridge, MA, USA. 
Fig. 1. Mean $( \pm \mathrm{SE})$ perch heights of $A$. sagrei shift higher $\left(\mathrm{F}_{1,7}=17.2, \mathrm{p}=0.004\right.$ repeated measures MANOVA; Effect size $(\log$ ratio $)=0.79)$ on islands after the experimental introduction of the predatory lizard L. carinatus. Islands on which lizards were extirpated during the course of the experiment (see text) were not included in this or subsequent analyses.

444 Fig. 2. Mean $( \pm \mathrm{SE})$ perch diameters of $A$. sagrei decrease $\left(\mathrm{F}_{1,7}=5.3, \mathrm{p}=0.05\right.$ repeated measures

445 MANOVA; Effect size $(\log$ ratio $)=1.27)$ on islands after the experimental introduction of the predatory lizard L. carinatus.

Fig. 3. Mean $( \pm \mathrm{SE})$ densities of $A$. sagrei on islands with and without the introduced predatory lizard $L$. carinatus. Also included are mean $( \pm \mathrm{SE})$ densities of $L$. carinatus after introduction. See text for statistical analysis.

452 Fig, 4. Changes in habitat use and pattern of natural selection from Losos et al. (2006). For use of the 453 ground (top) and perch diameter (middle), data from May 2003 represents habitat use before the initiation 454 of the experiment. All data are for individuals initially measured and marked in May 2003. Lizards grew 455 throughout the experiment, probably explaining the increase in perch diameter on control islands (an 456 intraspecific relationship between body size and perch diameter is well established in Anolis lizards). 457 (bottom) Selection gradients were calculated for two time periods, May 2003 to November 2003 and 458 November 2003 to May 2004. Selection gradients in the figure were adjusted for log-transformed island 459 area (included in the repeated-measures analysis as a covariate) by using least squares means from the 460 ANCOVA. Open symbols indicate control islands; filled symbols, introduction islands. Error bars $\pm \mathrm{SE}$. 
462 Fig. 5. Mean $( \pm$ SE) tibia length for treatment islands with introduced L. carinatus and control islands

463 with only $A$. sagrei $(\mathrm{p}=0.53$ repeated measures MANOVA). Note that this measure was taken with $\mathrm{x}-$

464 rays and Figure 3's measure was done by hand, as well as being hindlimb not tibia. The correlations

465 between the hindlimb measures taken by hand and the tibia by $\mathrm{x}$-ray are very high: males $\mathrm{r}=0.98(\mathrm{~N}=$

466 15), females $r=0.92(\mathrm{~N}=12)$ using data from mainland Great Abaco.

467

468

Fig. 6. Mean $( \pm \mathrm{SE})$ relative limb length (residuals from the tibia length vs. snout-vent length regression,

469 separate by sex) across all islands has fluctuated over the 19-year study period with little net change

470 (year-to-year change results from within-island evolution, population extinction, and the inclusion of

471 different islands at different points in the study; trends are similar when only the 9 islands sampled across

472 the 19-year period are considered [results not shown]). Limb values increase after hurricanes $(\mathrm{P}=0.005$,

473 see text).

474

475

476

477

478

479

480

481

482

483

484

485

486

487 
495 Thomas Schoener, David Spiller: Department of Evolution and Ecology,

496 University of California, Davis CA 95616 (twschoener@ucdavis.edu,

497 daspiller@ucdavis.edu)

498

499 Jason Kolbe: Department of Biological Sciences, University of Rhode Island,

500 Kingston, RI 02881 (jjkolbe@uri.edu)

501

502 Manuel Leal: Division of Biological Sciences, University of Missouri, Columbia, 503 MO 65211 (lealm@missouri.edu)

504

505 Jonathan Losos: Museum of Comparative Zoology and Department of Organismic 506 and Evolutionary Biology, Harvard University, Cambridge, MA 02138

507 (jlosos@oeb.harvard.edu)

508 
$\left.{ }^{5}\right]$ - A. sagrei with L. carinatus

- A. sagrei without L. carinatus

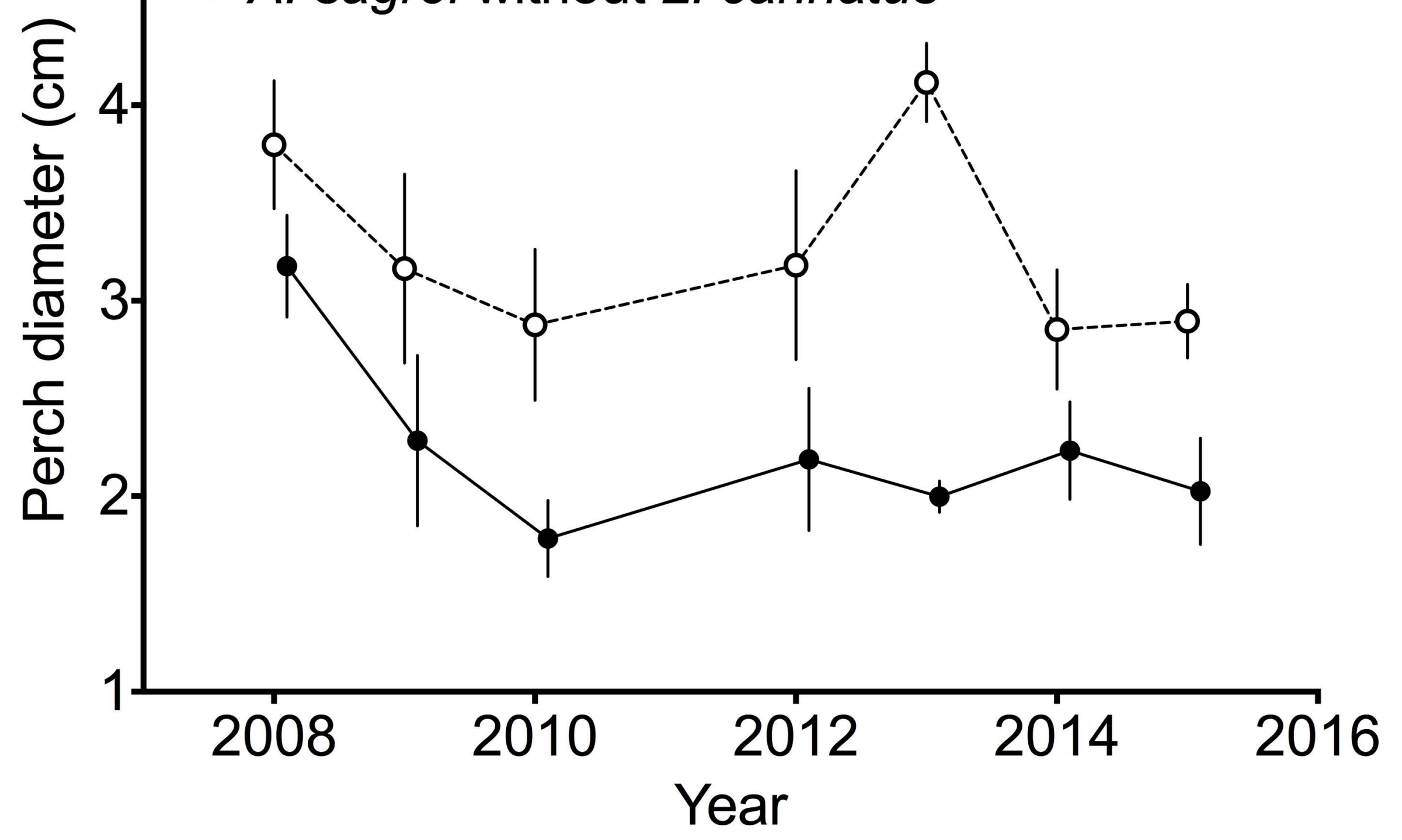



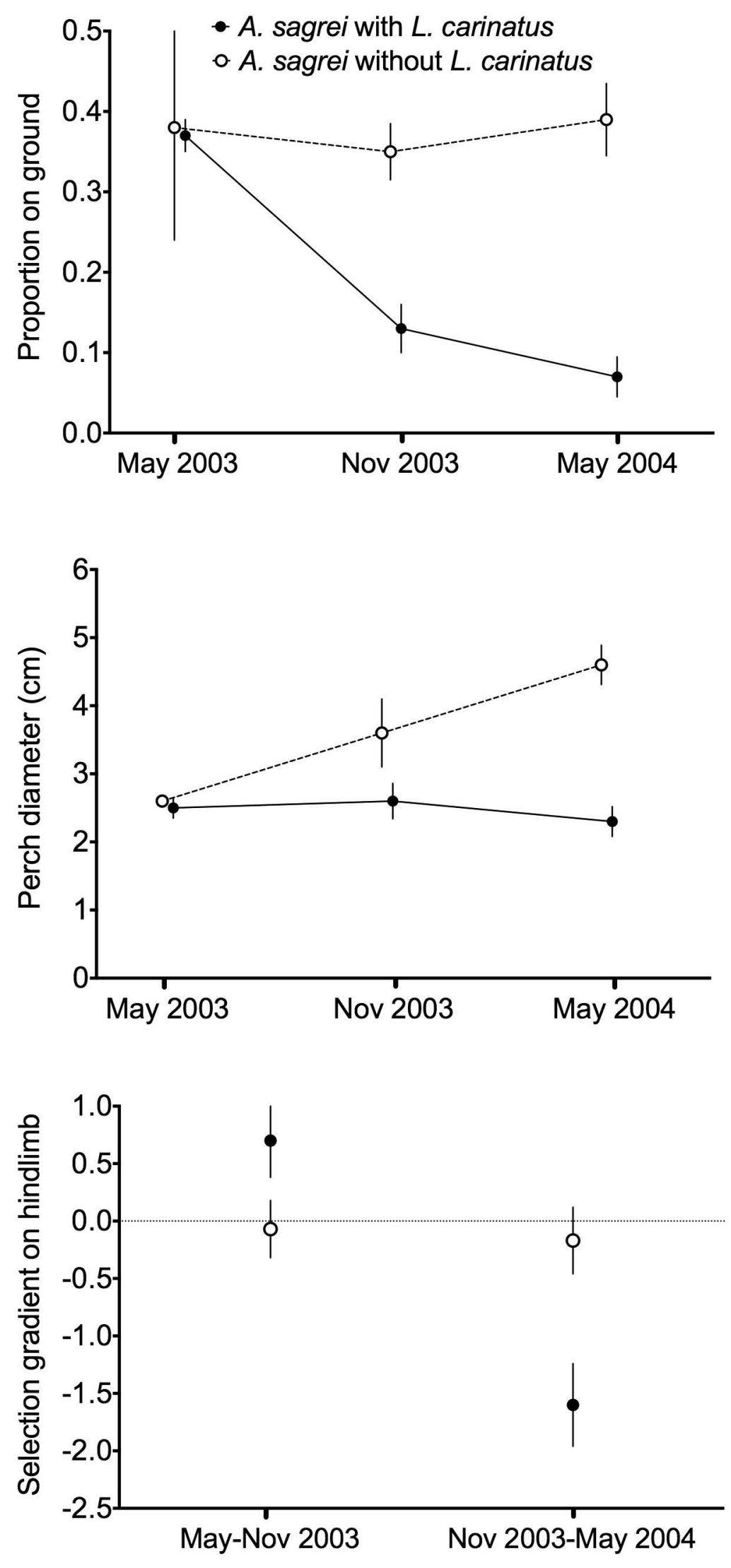


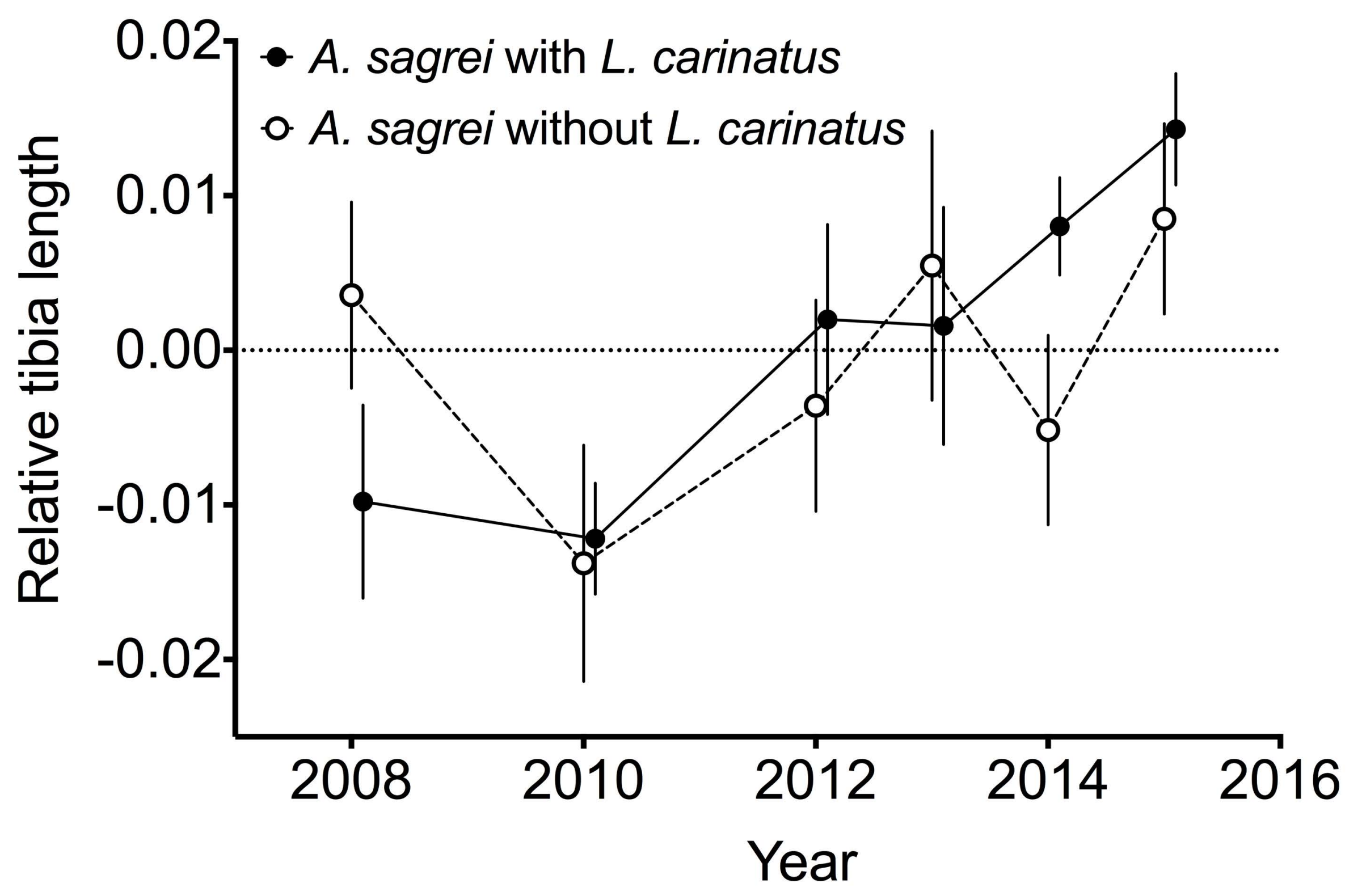




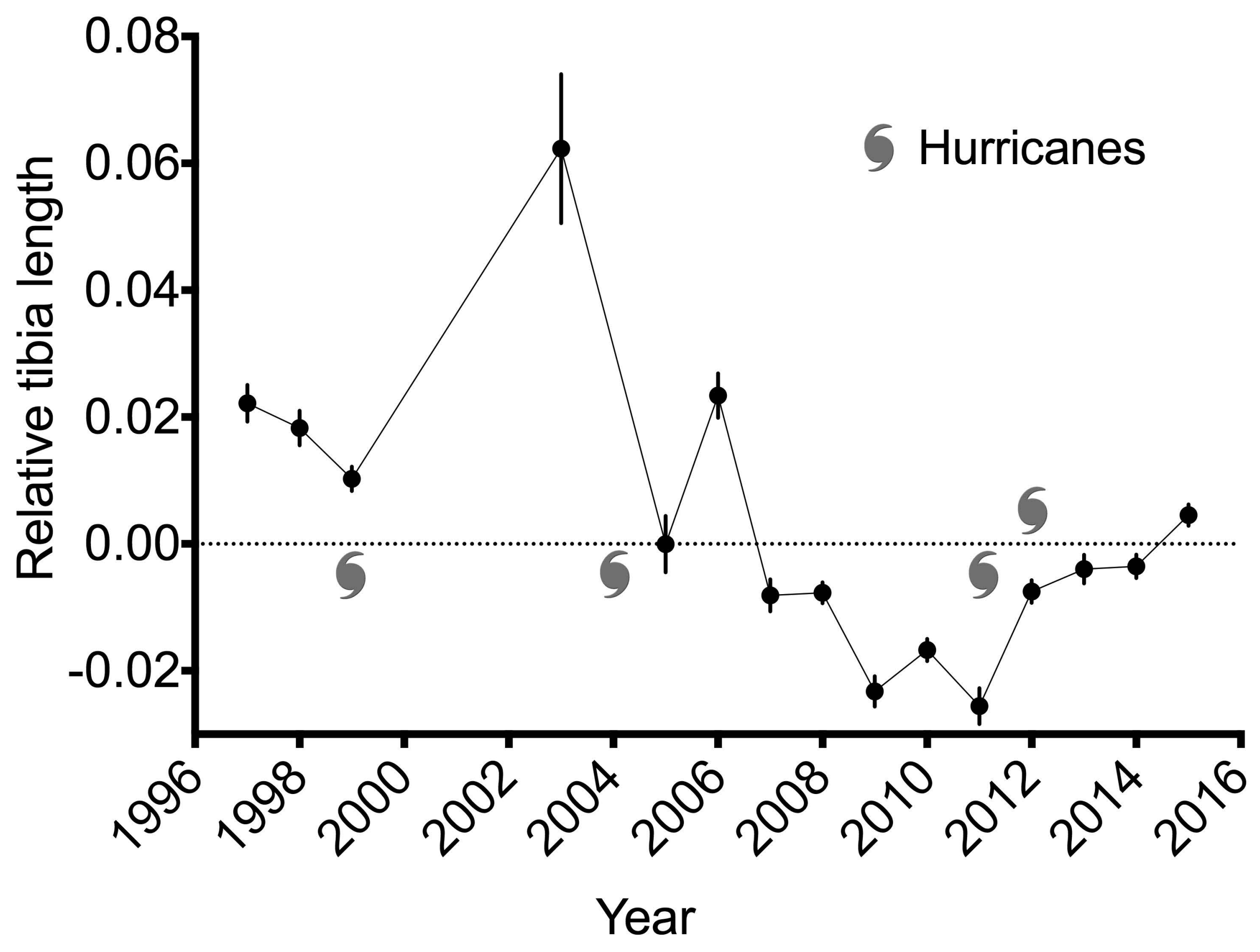

